\title{
BMJ Open Social support as a mediator between problem behaviour and gambling: a cross-sectional study among 14-16-year-old Finnish adolescents
}

Tiina Räsänen, ${ }^{1}$ Tomi Lintonen, ${ }^{2}$ Asko Tolvanen, ${ }^{3}$ Anne Konu ${ }^{1}$

To cite: Räsänen T, Lintonen T, Tolvanen A, et al. Social support as a mediator between problem behaviour and gambling: a crosssectional study among 14-16-year-old Finnish adolescents. BMJ Open 2016;6:e012468.

doi:10.1136/bmjopen-2016012468

- Prepublication history for this paper is available online. To view these files please visit the journal online (http://dx.doi.org/10.1136/ bmjopen-2016-012468).

Received 30 April 2016 Revised 3 November 2016 Accepted 8 November 2016

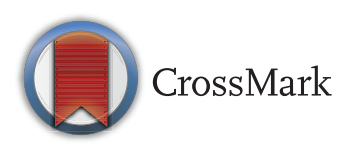

For numbered affiliations see end of article.

Correspondence to Dr Tiina Räsänen; rasanen. tiina.a@student.uta.fi

\section{ABSTRACT}

Background: During the adolescent period, risktaking behaviour increases. These behaviours can compromise the successful transition from adolescence to adulthood. The purpose of this study was to examine social support as a mediator of the relation between problem behaviour and gambling frequency among Finnish adolescents.

Methods: Data were obtained from the national School Health Promotion Study (SHPS) from the years 2010 and 2011 ( $N=102545)$. Adolescents were classified in the most homogeneous groups based on their problem behaviour via latent class analysis.

Results: Path analysis indicated that social support was negatively associated with problem behaviour, and problem behaviour and social support were negatively related (except for social support from friends among boys) to gambling. Social support from parents and school mediated, albeit weakly, the relations between problem behaviour and gambling among girls and boys. Conclusions: Problem behaviour may affect gambling through social support from school and parents. Thus prevention and intervention strategies should focus on strengthening adolescents' social support. In addition, because of the clustering of different problem behaviours instead of concentrating on a single form of problem behaviour multiple-behaviour interventions may have a much greater impact on public health.

\section{INTRODUCTION}

During the adolescent period, risk-taking behaviour increases. ${ }^{1}$ Risk-taking includes behaviours that are done under one's own volition, have uncertain outcomes and can compromise the successful transition from adolescence to adulthood. ${ }^{2}{ }^{3}$ Risk-taking behaviours also manifest in the form of problem behaviours, actions that are socially disapproved and result in social sanctions. These behaviours can co-occur; thus, involvement in one problem behaviour increases the risk of involvement in other problem behaviours, which is known as problem

\section{Strengths and limitations of this study}

- Large scale, population-based study explored the relationship between gambling, problem behaviour and social support.

- Studies have examined pathways from social support to both gambling and other problem behaviours, but research that tries to explain how adolescents' access to social support accounts for the association between gambling frequency and problem behaviour, is lacking.

- Temporal relationship between these factors remains unclear, because of the cross-sectional nature of the study.

- It may be that the final sample did not include the adolescents who were engaging in the highest levels of gambling and the highest levels of problem behaviour.

- Since this study was based solely on adolescent self-reports, there is the possibility of over or under-reporting.

behaviour syndrome. ${ }^{4}$ Gambling may be a component of the problem behaviour syndrome: problem gambling and regular gambling (at least once a week) are associated with conduct disorder, substance use and delinquency. ${ }^{6-9}$ However, it is not known if non-problem gambling and gambling that is not necessarily regular is related to the problem behaviour syndrome. In Finland in 2010 gambling was allowed for adolescents aged 15 years and over (except Internet and casino gambling) and in 2011, 15-year olds could legally gamble at slot machines (all other gambling games had age limit of 18 years), which are widely available in Finland. Adolescents have also had positive attitudes towards gambling in Finland. ${ }^{10}$ Likewise, studies have shown that parents and teachers do not think that gambling is a great concern among youth. ${ }^{11} 12$

According to problem behaviour theory, it is the balance between protective and risk 
factors that determines ones' involvement in problem behaviour. ${ }^{5}$ Social support provided by individuals and institutions can be described as interpersonal relationships that influence an individual's functioning. Social support is parents' closeness, monitoring and caring, teachers' interest in their students, and friends' supportiveness. ${ }^{13}$ Studies have shown that social support from parents, friends and school all play a crucial role in adolescents' problem behaviour. ${ }^{14-16}$ There is also some evidence indicating that family characteristics influence adolescents' gambling. ${ }^{17}$ Specifically, higher levels of parental attachment, monitoring and supervision are linked to decreased gambling, while lower levels of parental trust and communication are associated with increased gambling. ${ }^{18}$ Low levels of parental monitoring of adolescents is also associated with problem gambling during young adulthood. ${ }^{19}$ Additionally, adolescent problem gamblers tend to perceive lower levels of familial and peer support. ${ }^{20}$ While previous studies have examined shared predictors between gambling, problem behaviours and parenting, the findings of these studies do not provide evidence that parental supervision or monitoring are related to gambling as it is the case for other problem behaviours. ${ }^{21}{ }^{22}$ Moreover, friends' approval of gambling, associating with deviant peers, associating with friends who gamble and having friends who have gambling problems are associated with adolescent gambling. ${ }^{823} 24$ However, the only school characteristics that have been studied in the context of gambling are suspension rates, low school commitment and schools' rewards for prosocial involvement. These were either weakly or not at all associated with gambling. ${ }^{25} 26$ Studies examining the associations between schools' social support and gambling, are lacking.

Earlier studies have demonstrated that there are gender differences in gambling as well as problem behaviour. For example, gambling is more common among men ${ }^{27}$ and men also tend to start gambling at a younger age. ${ }^{28}$ Additionally, men have a higher risk for heavy alcohol use and smoking. ${ }^{29}{ }^{30}$ However, little is known about gender differences in relation to co-occurrence of gambling frequency and problem behaviours. It is also unclear if there are gender differences in associations between gambling, problem behaviour and social support.

In studies that assess gambling, problem behaviour and risk/protective factors, a limited number of problem behaviours (eg, gambling, substance use and delinquency) are examined and the focus is on parental monitoring, individual factors (impulsivity, moral disengagement) and peer delinquency, ${ }^{21} \quad 223132$ thereby excluding social support from important individuals and institutions, like friends and school. Previous studies have examined pathways from social support to both gambling and other problem behaviours, but research that tries to explain how adolescents' access to social support accounts for the association between gambling frequency and problem behaviour, is lacking. Thus, the role of social support in the association between problem behaviour and gambling has not been investigated. As earlier studies have shown that gambling is associated with problem behaviour and the degree of social support that an adolescent receives is related to both gambling frequency and problem behaviour; it is reasonable to expect that social support plays an important role in the extent to which problem behaviours are related to gambling frequency. Therefore, using a population-based survey of 8th and 9th grade boys and girls, the aim of this study was to investigate the relations between problem behaviour and gambling frequency, and social support as a potential mediator of this association (ie, serve as a protective factor). It is assumed that higher social support would be negatively associated with problem behaviour and gambling.

\section{METHOD \\ Setting}

In Finland, compulsory basic comprehensive school starts at age 7 (1st grade) and ends at the age of 16 years (9th grade). During the 8 th and 9 th grade boys and girls are between 14 and 16 years of age.

The Finnish gambling system is based on a state monopoly; the profits are returned to society and used for common good. In addition, the games are widely available in public places. The gambling age limit was set to 18 years in October 2010. The limit was also applied to slot machines in July 2011, and prior to that the age limit was age 15 years. At the time of survey completion, the age limit for gambling was 18 years and 15 years for slot machines.

\section{Data}

Data were obtained from the national School Health Promotion Study (SHPS) in 2010 and 2011, which included questions on adolescents' gambling, problem behaviour and social support. In 2010, the study was conducted in southern, eastern and northern Finland and in western and central Finland in 2011. Thus, the 2010 and 2011 surveys cover all of Finland, and in each year only a few municipalities refuse to participate. ${ }^{33}$ The municipalities that did not participate do not differ from the others and this part of the drop-out is not likely to pose a threat to generalisability. In $2010,78 \%$ of Finnish 8th and 9th graders were surveyed, and in 2011 $81 \%$ of Finnish 8 th and 9th graders participated in the study. Respondents who had not answered over half of the questions, or had not expressed their sex or grade, were removed. Also those who were not in school when survey was conducted or could not answer independently did not participate. ${ }^{33}$ SHPS is a cross-sectional survey administered throughout the school day in the 8th and 9th grades of lower secondary schools. Answering was voluntary. Parental consent was not required according to ethical guidelines in Finland; generally, surveys conducted during school days do not 
need parental permission. In total, 102545 8th (mean age $=14.9, \mathrm{SD}=0.4$ ) and 9th (mean age $=15.9, \mathrm{SD}=0.4$ ) grade students participated in the study. Forty-nine per cent of survey respondents were boys.

\section{Measures}

\section{Problem behaviour}

Problem behaviour was measured through 11 different forms of problem behaviours concerning adolescents' truancy, bullying, delinquency, smoking, using snuff, alcohol drinking, drunkenness-related drinking, using alcohol and medicine for intoxication, using medicine for intoxication, glue-sniffing and drug use. More detailed information about questions regarding problem behaviour can be found elsewhere. ${ }^{34}$ Since problem behaviour indicator included measures with multiple behaviour types and responses, which were not necessarily identically scaled, latent classes were estimated. Based on latent class analysis (LCA) adolescents were divided into four groups. From these groups those who participated in problem behaviour the most and the least were selected from the data to study extremities of the problem behaviour phenomenon.

\section{Social support from friends}

Social support from friends was requested by question: Do you have at this moment any close friend whom you can talk with confidentially almost everything? Alternatives were I do not have any friends, one close friend, two close friends and several close friends.

\section{Social support from school}

Social support from school based on three statements and two questions about schools' and teachers' support. Statements were: teachers encourage me to impress my own opinions at classes, teachers are interested about how I am doing and teachers are treating students fairly. The scale for these was totally agree, agree, disagree and totally disagree. Students were also asked: do you have troubles getting along with your teachers. Alternatives were not at all, fairly little, fairly much and very much. As well adolescents were requested if they had troubles with school work, how often they got help from school. Alternatives were always when I need it, most of the time, rarely and almost never. All of the statements and questions were coded from one to four, four indicating good social support. From these five variables the sum variable was created, which had one component structure with Cronbach's $\alpha$ value of 0.7 .

\section{Social support from parents}

Social support was examined by four questions. Students were asked do their parents know all of his/her friends. This question had alternatives both parents do (coded as three), only mother/father knows (coded as one) and neither of them know (coded as zero). Second question was, do your parents know where you spent your Friday and Saturday evenings, which had alternatives they know always (coded as three), know sometimes (coded as one) and most of the time they do not know (coded as zero). Adolescents were also asked can they talk with their parents: almost never (coded as zero), sometimes (coded as one), fairly often (coded as two) and often (coded as three). The last question was if adolescents had troubles with school work, how often they got help from home. Alternatives were always when I need it (coded as three), most of the time (coded as two), rarely (coded as one) and almost never (coded as zero). These four questions measuring the social support from parents had one component structure, which had Cronbach's $\alpha$ value of 0.6.

\section{Gambling}

Gambling was requested by one question: How often do you gamble? Alternatives were on 6-7 days per week, on 3-5 days per week, on 1-2 days per week, less than once a week, less than once a month, I have not gambled during previous year.

\section{Statistical analysis}

Basic statistical analyses were conducted with IBM SPSS Statistics V.22, and structural equation modelling was conducted with Mplus V.7.0. ${ }^{35}$ Basic statistical analyses included $\chi^{2}$-test (for categorical data) and Mann-Whitney U test (for continuous data), which are used to detect statistically significant difference between two or more groups. LCA was used to identify groups of adolescents based on their involvement in different problem behaviours. The purpose was to identify the most homogeneous groups that include extreme classes of problem behaviour. LCA provides fit statistics and significance tests to assess the number of classes that best fit the data. ${ }^{36}$ To select the number of classes for the model, the analysis was first run with one class, then with two and three classes and so on. This procedure was followed until to the highest possible number of classes were run (which was in this case 11). Model solutions were assessed by examining the entropy values (near 1.0), the Lo-Mendell-Rubin test (a $\mathrm{p}$ value that provides information about statistically significant improvement in fit for the inclusion of an additional class) as well as the interpretation of the results. ${ }^{37}$ For further analysis, all individuals were classified into classes where class membership was based on the highest posterior probabilities.

Based on the LCA results, path analysis was conducted for those who participated in the most and the least problem behaviours. The analysis was conducted to examine if social support mediates the association between problem behaviour and gambling. In this model, gambling frequency was regressed on the three forms of social support, and forms of social support were then regressed on problem behaviour (figure 1). Analyses were run separately for 8th and 9th grade girls and boys given the possible differences in the relation between gambling and problem behaviour. All the 
Figure 1 Path model of the associations between the social support from friends (SSF), social support from school (SSS), social support from parents (SSP), problem behaviour and gambling frequency among 8th and 9th grade boys and girls.

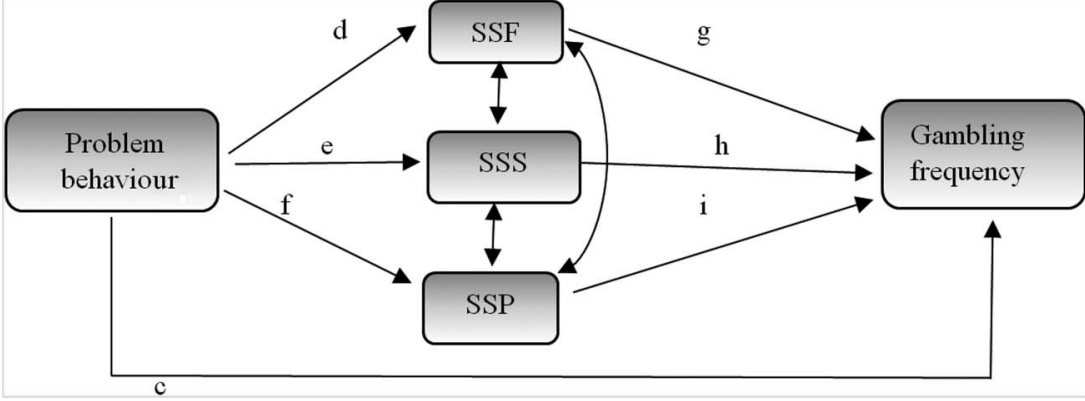

models were saturated, so the model fits were necessarily perfect.

\section{RESULTS}

\section{Latent class analysis}

Adolescents who did not gamble during the previous year $(37.3 \%)$ or had missing values on the main outcome variable $(1.3 \%)$ were excluded. This was carried out because we were only interested in adolescents who were gambling. For the remaining 62956 individuals, LCA was conducted separately for 8 th and 9 th grade girls and boys to identify groups of adolescents based on their problem behaviours. For all 8th and 9th grade girls and boys, the optimal model had four classes with entropy values ranging from 0.88 to 0.83 . The reasonably high entropies and the Lo-Mendell-Rubin test $p$ values suggested a good model fit for the four class model. However, among 8th grade girls and 9th grade boys, the $\mathrm{p}$ values were lower than 0.05 , indicating that the five or more class model was a better fit. However, after taking into account the entropies and the interpretation of the results, the four class model was chosen for all participants (table 1).

Class 1 included adolescents who participated in all forms of problem behaviours at the highest frequency (see ref. 33). For example, adolescent in class 1 smoked at least daily, drank alcohol on a weekly basis and had tried drugs at least once. Youth in class 2 also participated in problem behaviour, but their participation in problem behaviours was more experimental. In addition, most of the youth in class 2 did not use alcohol with medicine for intoxication, use medicine for intoxication and did not participate in glue sniffing. In class 3, adolescents smoked tobacco less often than once a week and consumed alcohol only a couple of times a month. The youths in class 4 did not participate in any form of problem behaviour. From these groups, class 1 and class 4 were selected, including adolescents participating regularly in all examined problem behaviours and those not participating in any, which allowed for the study of the extremes of problem behaviour $(\mathrm{N}=29870)$.

\section{Gambling, problem behaviour and social support}

The next set of analyses compared the adolescents who participated in the most problem behaviour and the adolescents that participated in the least problem behaviour. Boys gambled more than girls did $\left(\chi^{2}\right.$ (4) $=3280.182, \mathrm{p}<0.001)$; however, participation in problem behaviour was more common among girls $\left(\chi^{2}\right.$ (1) $=1313.636, \mathrm{p}<0.001$ ) (table 2). Girls experienced more social support from friends $\left(\chi^{2}(4)=553.19, \mathrm{p}<0.001\right)$, and boys received more support from school $(\mathrm{U}=88080721, \mathrm{p}<0.001)$ and from parents $(\mathrm{U}=84026360$, $\mathrm{p}<0.001$ ) (table 2). 9th graders gambled (boys: $\chi^{2}(4)$ $=11395 \mathrm{p}=0.022)$, (girls: $\left.\chi^{2} \quad(4)=25.416, \mathrm{p}<0.001\right)$ and participated in problem behaviour (boys: $\chi^{2}$ (1) $=126.024, \quad \mathrm{p}<0.001), \quad\left(\right.$ girls: $\left.\chi^{2} \quad(1)=367.030, \quad \mathrm{p}<0.001\right)$ more often than 8 th graders. Eighth grade boys also experienced more social support from friends $\left(\chi^{2}(3)\right.$ $=25.933), \mathrm{p}<0.001)$, school $(\mathrm{U}=52467017.0, \mathrm{p}<0.01)$, and parents $(51780278.5, \mathrm{p}<0.001)$ than 9th grade boys. Eighth grade girls experienced more social support from school $(\mathrm{U}=9696512.5, \quad \mathrm{p}<0.001)$ and parents $(\mathrm{U}=9817557.0, \mathrm{p}<0.01)$, but there were no statistical differences in social support from friends (table 2). Among girls who gambled on weekly basis, $50 \%$ of 8 th graders and $74 \%$ of 9 th graders also participated in problem behaviour. Among the boys, the percentage was $14 \%$ for 8 th graders and $22 \%$ for 9 th graders.

\section{Path analysis}

The standardised parameter estimates ( $\beta$ ) shown in table 3 indicated that problem behaviour was significantly and positively related to adolescents' gambling frequency (path $\mathrm{c}$ ). The $\beta$ indices also showed that there was a significant negative association between problem behaviour and the different types of social support; however, among 9th grade girls, social support from friends was not statistically significant (paths d-f). Social support from parents and school were negatively related with gambling (paths $\mathrm{g}$ and $\mathrm{i}$ ). Among boys, social support from friends was significant and positively associated with gambling; however, among girls social support from friends was significantly and negatively associated with gambling (path $\mathrm{h}$ ) (table 3; also see figure 1).

The statistically significant albeit very small indirect effects indicated that social support mediated the relationship between problem behaviour and gambling frequency, but social support from friends did not mediate this association. The total effect of problem behaviour 


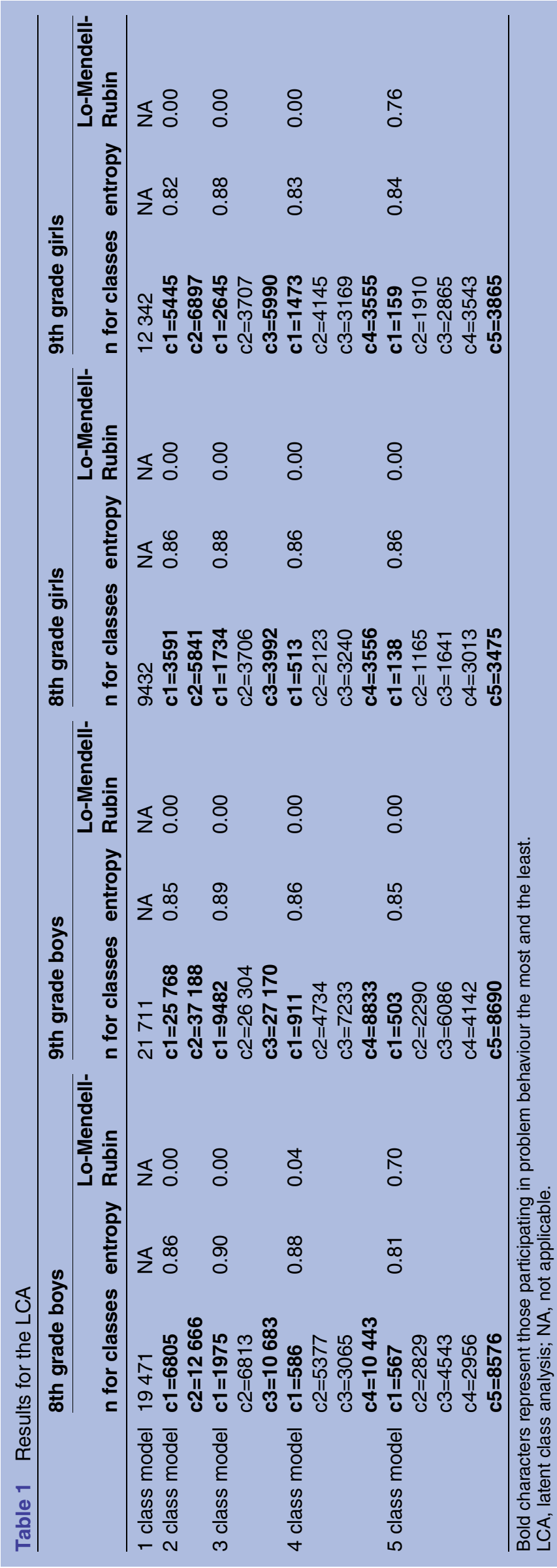

on problem gambling frequency consisted of a direct effect and an indirect effect through social support (table 3). Forty-two per cent and $49 \%$ of the variance $\left(\mathrm{R}^{2}\right)$ was explained by the association between gambling and social support for 8 th grade and 9th grade boys, respectively. For 8 th grade girls, $63 \%$ of the variance was explained and $69 \%$ of the variance was explained for 9 th graders.

\section{DISCUSSION}

This large scale, population-based study explored the relationship between problem behaviour, gambling and social support among 14-16-year-old adolescents. The main purpose of the study was to examine whether social support would mediate this association. Social support from parents and school mediated weakly the relations between problem behaviour and gambling among girls and boys. Social support from friends did not mediate this association. Thus, the data suggest that the relation between problem behaviour and gambling can be explained only by the degree of social support received from school and parents; there may be other issues or phenomena that are more important in mediating this association.

In accordance with the Mun $e t a l^{88}$ research, this study indicated that problem behaviour did cluster at the both ends of the lifestyle spectrum (ie, 'problem' or 'nonproblem' behaviour patterns among adolescents). Within these two classes, there were adolescents who participated regularly in all forms of problem behaviours and those who did not participate in any problem behaviours. Additionally, this study found that problem behaviour and gambling were associated, with problem behaviour increasing as the frequency of gambling increased. This is similar to previous studies. ${ }^{72} 32$ These results may indicate that involvement in one problem behaviour also increases the risk of involvement in other problem behaviours, as demonstrated by problem behaviour theory. ${ }^{4} 13$

To the best of our knowledge, this is the first study to examine whether social support from school is associated with gambling frequency. Earlier studies have assessed school characteristics, such as suspension rates, school commitment and schools' rewards for prosocial involvement. ${ }^{25} 26$ In the current study, social support from school was significantly related to gambling frequency, with lower support related to higher gambling participation. In addition, low social support from parents and friends was related to increased gambling, which is consistent with the findings of Hardoon et al. ${ }^{20}$ In their study, they reported significant differences between gambling severity groups in their levels of family and peer support. Specifically, their results indicated that non-gamblers and social gamblers experienced more social support than at-risk and pathological gamblers. However, in the current study, this pattern was found only for female adolescent gamblers. For boys, 
Table 2 Adolescents' involvement in gambling and problem behaviour, and experiencing SSF, SSS and SSP based on their sex and grade

\begin{tabular}{|c|c|c|c|c|c|c|}
\hline & $\begin{array}{l}\text { 8th grade } \\
\text { boys }\end{array}$ & $\begin{array}{l}\text { 9th grade } \\
\text { boys }\end{array}$ & $\begin{array}{l}\text { 8th grade } \\
\text { girls }\end{array}$ & $\begin{array}{l}\text { 9th grade } \\
\text { girls }\end{array}$ & $\begin{array}{l}\text { Boys vs } \\
\text { girls }\end{array}$ & $\begin{array}{l}8 \text { vs } 9 \\
\text { grade }\end{array}$ \\
\hline \multicolumn{7}{|l|}{ Per cent } \\
\hline Gambling & & & & & $\begin{array}{l}p<0.001 \\
\text { eta: } 0.278\end{array}$ & $\begin{array}{l}p=0.022 \\
\text { eta:0.01 }\end{array}$ \\
\hline Less than once a month & 38.4 & 34.1 & 73.7 & 69.9 & & \\
\hline Less than once a week & 28.8 & 30.3 & 15.7 & 18.1 & & \\
\hline $1-2$ days per week & 18.7 & 19.6 & 5.0 & 6.2 & & \\
\hline $3-5$ days per week & 8.1 & 9.3 & 2.2 & 3.0 & & \\
\hline 6-7 days per week & 6.1 & 6.8 & 3.4 & 2.8 & & \\
\hline $\begin{array}{l}\text { Participating in problem } \\
\text { behaviour } \\
\text { SSF }\end{array}$ & 5.3 & 9.3 & 12.6 & 29.3 & $\begin{array}{l}p<0.001 \\
\text { eta: } 0.210 \\
p<0.001 \\
\text { eta: } 0.101\end{array}$ & $\begin{array}{l}p<0.001 \\
\text { eta: } 0,14 \\
p=0.029 \\
\text { eta: } 0.015\end{array}$ \\
\hline Do not have any friends & 13.7 & 15.3 & 7.1 & 6.7 & & \\
\hline One close friend & 24.1 & 26.0 & 20.7 & 21.6 & & \\
\hline Two close friends & 20.5 & 19.1 & 27.5 & 27.2 & & \\
\hline Several close friends & 40.9 & 39.0 & 44.5 & 44.3 & & \\
\hline $\begin{array}{l}\text { Missing values } \\
\mathrm{x}(\mathrm{SD})\end{array}$ & 0.8 & 0.7 & 0.2 & 0.3 & & \\
\hline SSS & $2.8(0.5)$ & $2.7(0.6)$ & $2.7(0.5)$ & $2.7(0.6)$ & $\begin{array}{l}p<0.001 \\
\text { eta: } 0.003\end{array}$ & $\begin{array}{l}p<0.001 \\
\text { eta: } 0.002\end{array}$ \\
\hline SSP & $2.2(0.6)$ & $2.2(1.2)$ & $2.1(0.7)$ & $2.0(0.7)$ & $\begin{array}{l}p<0.001 \\
\text { eta: } 0.005\end{array}$ & $\begin{array}{l}p<0.001 \\
\text { eta: } 0.001\end{array}$ \\
\hline $\mathrm{n}$ & 11029 & 9744 & 4069 & 5028 & 29870 & 29870 \\
\hline
\end{tabular}

social support from friends was positively related to gambling frequency. It might be that gambling is social activity for boys, but for girls gambling may be an activity that substitutes normal social contacts. Problem gambling may occur in the absence of friends, whereas nonproblematic gambling may be part of a social pastime. ${ }^{20}$ Gambling was more common among boys, which is consistent with previous studies; ${ }^{623}$ however, over $50 \%$ of
8 th grade and $74 \%$ of 9 th grade girls who gambled on a weekly basis participated in problem behaviour. This indicates that active gambling among girls is strongly linked to problem behaviour and thus a phenomenon that should be studied more extensively.

Although the findings of this study indicated that social support mediated the association between problem behaviour and gambling frequency, the

Table 3 Path model of the direct and indirect effects between the ssf, sss, ssp, pb and gambling frequency (gb) among 8th and 9th grade boys and girls

\begin{tabular}{|c|c|c|c|c|}
\hline & $\begin{array}{l}8^{\text {th }} \text { grade boys } \\
\beta\end{array}$ & $\begin{array}{l}9^{\text {th }} \text { grade boys } \\
\beta\end{array}$ & $\begin{array}{l}8^{\text {th }} \text { grade girls } \\
\beta\end{array}$ & $\begin{array}{l}9^{\text {th }} \text { grade girls } \\
\beta\end{array}$ \\
\hline Direct effect c (pb to gb) & $0.35^{\star \star \star}$ & $0.36^{\star * *}$ & $0.34^{\star * *}$ & $0.36^{\star \star \star}$ \\
\hline Path from pb to sss (path e) & $-0.30^{\star \star *}$ & $-0.36^{\star \star \star}$ & $-0.43^{\star \star \star}$ & $-0.46^{\star \star \star}$ \\
\hline Path from pb to ssf (path d) & $-0.09^{\star \star \star}$ & $-0.07^{\star \star \star}$ & $-0.08^{\star \star \star}$ & -0.01 \\
\hline Path from pb to ssp (path f) & $-0.37^{\star * *}$ & $-0.39^{* * *}$ & $-0.19^{\star \star \star}$ & $-0.50^{\star \star \star}$ \\
\hline Path from sss to gb (path h) & $-0.11^{\star \star *}$ & $-0.13^{\star \star \star}$ & $-0.06^{\star \star}$ & $-0.11^{\star \star \star}$ \\
\hline Path from ssf to gb (path g) & $0.07^{* \star *}$ & $0.04^{\star \star \star}$ & $-0.08^{\star \star \star}$ & $-0.09^{\star \star \star}$ \\
\hline Path from ssp to gb (path i) & $-0.09^{\star \star \star}$ & $-0.08^{* * *}$ & $-0.10^{\star \star \star}$ & $-0.06^{\star \star \star}$ \\
\hline Total effect $c^{\prime}$ (pb to $\left.g b\right)$ & $0.41^{* * *}$ & $0.43^{* * *}$ & $0.42^{\star \star \star *}$ & $0.44^{\star \star \star}$ \\
\hline Total indirect effect $c-c^{\prime}$ & $0.06^{\star \star \star}$ & $0.07^{\star * *}$ & $0.08^{\star \star \star}$ & $0.08^{\star \star \star}$ \\
\hline Path from $\mathrm{pb}$ to sss to $\mathrm{gb}$ & $0.03^{\star \star \star}$ & $0.05^{\star \star \star}$ & $0.03^{\star *}$ & $0.05^{\star \star \star}$ \\
\hline Path from $\mathrm{pb}$ to ssf to $\mathrm{gb}$ & $-0.01^{\star * *}$ & $-0.00^{* * *}$ & $0.01^{\star * *}$ & 0.00 \\
\hline Path from $\mathrm{pb}$ to $\mathrm{ssp}$ to $\mathrm{gb}$ & $0.03^{\star \star \star}$ & $0.03^{\star \star \star}$ & $0.05^{\star \star \star}$ & $0.03^{\star \star \star}$ \\
\hline
\end{tabular}


temporal relationship between these factors remains unclear. Thus, additional research is needed using longitudinal data. Additionally, it is important to note that while social support from friends, parents and school were significantly associated with gambling, the path coefficients were low among boys and girls and may due to large sample size. Furthermore, path coefficients for the indirect effects were low. This may indicate that social support does not play a large in the association between problem behaviour and gambling. There may be additional factors that play a more important role in this association, such as having friends or parents who: gamble, have a gambling problem or participate in other problem behaviours or individual factors such as low self-control or conduct disorder. These types of factors have been examined in previous studies. $^{7818212324}$

Furthermore, gambling frequency was assessed by a single item, and there was no validated problem gambling screen used herein. However, the goal of the study was to study gambling involvement and its associations with problem behaviours and social support, not to identify problem gamblers. The survey did not collect additional information on gambling behaviour (eg, how much money is spent on gambling), nor was information about gambling types. Additionally, the definition of gambling was not given in the questionnaire, so adolescents could interpret gambling in many ways. ${ }^{34} 39$ Also we did not use a validated measure for social support. The internal consistency for the scale of 'social support from parents' was not optimal as indicated by the low value of Cronbach's $\alpha$. However, validity is supported by the fact that the principal component analysis indicated one component structure.

In addition, data were collected from $78 \%$ of Finnish 8th and 9th graders in 2010 and from $81 \%$ of Finnish 8th and 9th graders in 2011. However, it may be that the final sample did not include the adolescents who were engaging in the highest levels of gambling and the highest levels of problem behaviour. Moreover, since this study was based solely on adolescent self-reports, there is the possibility of over or under-reporting.

Despite the limitations, mediation effects were detected, which have theoretical importance as well as significant implications for intervention. Specifically, prevention and intervention strategies should focus on strengthening adolescents' social support from parents and school. In addition, because of the clustering of different problem behaviours and the fact that problem behaviour was linked to gambling, instead of concentrating on a single form of problem behaviour multiplebehaviour interventions may have a much greater impact on public health. ${ }^{40}$

\footnotetext{
Author affiliations

${ }^{1}$ School of Health Sciences, University of Tampere, Tampere, Finland

${ }^{2}$ Finnish Foundation for Alcohol Studies, Helsinki, Finland

${ }^{3}$ Department of Psychology, University of Jyväskylä, Jyväskylä, Finland
}

Contributors TR, AT, TL and AK were involved in study conception and design. TR, AT, TL and AK analysed and interpreted the data. TR drafted the manuscript. AT, TL and AK critically revised the manuscript.

Funding This study was financially supported by the Finnish Foundation for Alcohol Studies. The Finnish Foundation for Alcohol Studies had no involvement in the study design, data handling, writing or submission of the manuscript. The grants awarded by the Finnish Foundation for Alcohol Studies for gambling research are based on a government contract for studying gambling-related harm.

Competing interests None declared.

Ethics approval The ethical committee of Tampere University Hospital.

Provenance and peer review Not commissioned; externally peer reviewed.

Data sharing statement No additional data are available.

Open Access This is an Open Access article distributed in accordance with the Creative Commons Attribution Non Commercial (CC BY-NC 4.0) license, which permits others to distribute, remix, adapt, build upon this work noncommercially, and license their derivative works on different terms, provided the original work is properly cited and the use is non-commercial. See: http:// creativecommons.org/licenses/by-nc/4.0/

\section{REFERENCES}

1. Michael K, Ben-Zur H. Risk-taking among adolescents: associations with social and affective factors. J Adolesc 2007;30:17-31.

2. Igra $\mathrm{V}$, Irwin CE. Theories of adolescent risk-taking behavior. In: DiClemente RJ, Hansen WB, Ponton LE, eds. Handbook of adolescent health risk behaviour. New York: Plenum Press, 1996:35-51.

3. Leather NC. Risk-taking behaviour in adolescence: a literature review. J Child Healthcare 2009;13:295-304.

4. Jessor R, Jessor SL. Problem behavior and psychosocial development: a longitudinal study of youth. New York: Academic Press, 1977.

5. Jessor R, Turbin MS. Parsing protection and risk for problem behavior versus pro-social behavior among US and Chinese adolescents. J Youth Adolesc 2014;43:1037-51.

6. Barnes GM, Welte JW, Hoffman JH, et al. Gambling, alcohol, and other substance use among youth in the United States. J Stud Alcohol Drugs 2009;70:134-42.

7. Welte JW, Barnes GM, Tidwell MC, et al. Association between problem gambling and conduct disorder in a national survey of adolescents and young adults in the United States. J Adolesc Health 2009;45:396-401.

8. Gori M, Potente R, Pitino A, et al. Relationship between gambling severity and attitudes in adolescents: findings from a population-based study. J Gambl Stud 2015;31:717-40.

9. Yip SW, Desai RA, Steinberg MA, et al. Health/functioning characteristics, gambling behaviors, and gambling-related motivations in adolescents stratified by gambling problem severity: findings from a high school survey. Am J Addict 2011;20:495-508.

10. Salonen $\mathrm{AH}$, Castrén $\mathrm{S}$, Raisamo $\mathrm{S}$, et al. Attitudes towards gambling in Finland: a cross-sectional population study. BMC Public Health 2014;14:982.

11. Shead WN, Derewensky JL, Meerkamper E. Your mother should know: a comparison of maternal and paternal attitudes and behaviors related to gambling among their adolescent children. Int $J$ Ment Health Addiction 2011;9:264-75.

12. Derevensky JL, St-Pierre RA, Temcheff CE, et al. Teacher awareness and attitudes regarding adolescent risky behaviours: is adolescent gambling perceived to be a problem? J Gambl Stud 2014;30: 435-51.

13. Jessor R, Turbin MS, Costa FM, et al. Adolescent problem behavior in China and the United States: a cross-national study of psychosocial protective factors. J Res Adolesc 2003;13:329-60.

14. Dekovic M. Risk and protective factors in the development of problem behavior during adolescence. $J$ Youth Adolesc 1999;28:667-85.

15. Fleming $\mathrm{CB}$, Catalano RF, Haggerty KP, et al. Relationships between level and change in family, school, and peer factors during two periods of adolescence and problem behavior at age 19 . $J$ Youth Adolesc 2010;39:670-82.

16. Garnefski N, Diekstra RF. Perceived social support from family, school, and peers: relationship with emotional and behavioral problems among adolescents. J Am Acad Child Adolesc Psychiatry 1996;35:1657-64. 
17. McComb JL, Sabiston CM. Family influences on adolescent gambling behavior: a review of the literature. J Gamb/ Stud 2010;26:503-20.

18. Magoon ME, Ingersoll GM. Parental modeling, attachment, and supervision as moderators of adolescent gambling. J Gambl Stud 2006;22:1-22.

19. Lee GP, Stuart EA, lalongo NS, et al. Parental monitoring trajectories and gambling among a longitudinal cohort of urban youth. Addiction 2014;109:977-85.

20. Hardoon KK, Gupta R, Derevensky JL. Psychosocial variables associated with adolescent gambling. Psychol Addict Behav 2004;18:170-9.

21. Barnes GM, Welte JW, Hoffman JH, et al. Shared predictors of youthful gambling, substance use, and delinquency. Psychol Addict Behav 2005;19:165-74.

22. Wanner B, Vitaro F, Carbonneau R, et al. Cross-lagged links among gambling, substance use, and delinquency from midadolescence to young adulthood: additive and moderating effects of common risk factors. Psychol Addict Behav 2009;23:91-104.

23. Castrén S, Grainger M, Lahti T, et al. At-risk and problem gambling among adolescents: a convenience sample of first-year junior high school students in Finland. Subst Abuse Treat Prev Policy 2015;10:9.

24. Hanss D, Mentzoni RA, Blaszczynski A, et al. Prevalence and correlates of problem gambling in a representative sample of Norwegian 17-year-olds. J Gambl Stud 2015;31:659-78.

25. Lee GP, Martins SS, Pas ET, et al. Examining potential school contextual influences on gambling among high school youth. Am $J$ Addict 2014;23:510-17.

26. Scholes-Balog KE, Hemphill SA, Dowling NA, et al. A prospective study of adolescent risk and protective factors for problem gambling among young adults. J Adolesc 2014;37:215-24

27. Kristiansen $S$, Jensen SM. Prevalence of gambling problems among adolescents in the Nordic countries: an overview of national gambling surveys 1997-2009. Int J Soc Welfare 2011;20:75-86.

28. Burge AN, Pietrzak RH, Molina CA, et al. Age of gambling initiation and severity of gambling and health problems among older adult problem gamblers. Psychiatr Serv 2004;55:1437-9.
29. Schulte MT, Ramo D, Brown SA. Gender differences in factors influencing alcohol use and drinking progression among adolescents. Clin Psychol Rev 2009;29:535-47.

30. Helldán A, Helakorpi S, Virtanen S, et al. Health behaviour and health among the Finnish adult population. National Institute for Health and Welfare (THL), Report 15/2013, 2013. http://urn.fi/URN: ISBN:978-952-245-931-2

31. Barnes GM, Welte JW, Hoffman JH, et al. The co-occurrence of gambling with substance use and conduct disorder among youth in the United States. Am J Addict 2011;20:166-73.

32. Vitaro F, Brendgen M, Ladouceur R, et al. Gambling, delinquency, and drug use during adolescence: mutual influences and common risk factors. J Gambl Stud 2001;17:171-90.

33. Luopa $P$, Kivimäki $H$, Matikka A, et al. Nuorten hyvinvoint Suomessa 2000-2013-Kouluterveyskyselyn tulokset. [Wellbeing of adolescents in Finland 2000-2013. The Results of the School Health Promotion study]. National Institute for Health and Welfare (THL). Report 25/2014.

34. Räsänen T, Lintonen T, Konu A. Gambling and problem behavior among 14- to 16-year-old boys and girls in Finland. J Gambl Issues 2015;31:1-23.

35. Muthén LK, Muthén BO (1998-2015). Mplus user's guide. 7th edn Los Angeles, CA: 2015.

36. Nylund KL, Asparouhov T, Muthén BO. Deciding on the number of classes in latent class analysis and growth mixture modeling: a Monte Carlo simulation study. Struct Equ Model 2007;14:535-69.

37. Jung T, Wickrama KAS. An introduction to latent class growth analysis and growth mixture modeling. Soc Personal Psychol Compass 2008;2:302-17.

38. Mun EY, Windle M, Schainker LM. A model-based cluster analysis approach to adolescent problem behaviors and young adult outcomes. Dev Psychopathol 2008;20:291-318.

39. Räsänen $\mathrm{T}$, Lintonen $\mathrm{T}$, Joronen $\mathrm{K}$, et al. Girls and boys gambling with health and well-being in Finland. J Sch Health 2015;85:214-22.

40. Nigg CR, Allegrante JP, Ory M. Theory-comparison and multiple-behavior research: common themes advancing health behavior research. Health Educ Res 2002;17:670-9. 